\title{
Infección por el virus de la hepatitis E: clínica y epidemiología
}

\section{Clinical and Epidemiology of Hepatitis E Virus Infection}

María Camila López 0., ${ }^{1}$ Alejandra Duque Jaramillo, ${ }^{1}$ María Cristina Navas N. ${ }^{1}$

Grupo de gastrohepatología, Facultad de Medicina. Universidad de Antioquia. Medellín, Colombia.

Correspondencia: María Cristina Navas, correo: maria navas@udea.edu.co.

Fecha recibido: $10-07-07$

Fecha aceptado: 22-01-18

\section{Resumen}

El virus de la hepatitis $E$ es un patógeno hepatotrópico que se transmite por el agua y alimentos contaminados, y uno de los principales agentes etiológicos de hepatitis viral aguda de transmisión enteral en el mundo.

La infección por el virus de la hepatitis E usualmente es autolimitada; sin embargo, se han descrito casos de infección crónica en pacientes inmunocomprometidos. La infección autolimitada no requiere tratamiento; por el contrario, la infección crónica debe tratarse debido al riesgo de progresión a cirrosis o a alguna de las manifestaciones extrahepáticas reportadas.

En Colombia, la infección por el virus de la hepatitis $E$ no hace parte del diagnóstico rutinario de hepatitis virales, a pesar de que existe evidencia de la circulación del virus en el país.

El presente artículo de revisión tiene como objetivo describir las generalidades del virus de la hepatitis $\mathrm{E}$, así como la historia natural de la infección y los estudios realizados en Colombia que evidencian su presencia en el país. La revisión se realizó mediante una búsqueda de literatura en la base de datos PubMed, SciELO y ScienceDirect, de trabajos originales y revisiones de tema publicados entre el período 1983-2017.

\section{Palabras clave}

Virus de la hepatitis E, infección, revisión, Colombia.

\section{Abstract}

The hepatitis E virus, a hepatotropic pathogen transmitted by water and contaminated food, is one of the main etiological agents on the planet of enteral transmission of acute viral hepatitis.

Hepatitis E infections are usually self-limiting, but cases of chronic infection have been described in immunocompromised patients. While self-limiting infections do not require treatment, chronic infections should be treated because of risk of progression to cirrhosis and/or extra-hepatic manifestations.

In Colombia, hepatitis $\mathrm{E}$ infections are not included in the routine diagnosis of viral hepatitis, despite evidence of its presence in the country.

The objective of this review is to provide a general description of the hepatitis $E$ virus and the natural history of infections and to highlight studies carried out in Colombia showing its presence in the country. The review was carried out through a search in the PUBMED, SCIELO and ScienceDirect databases for of original papers and subject reviews published between 1983 and 2017.

\section{Keywords}

Hepatitis E virus, infection, revision, Colombia. 


\section{INTRODUCCIÓN}

El virus de la hepatitis E (VHE) se descubrió en 1983 mediante la autoinoculación de una muestra de materia fecal proveniente de un paciente (1). El voluntario desarrolló un cuadro de hepatitis viral aguda no A, no B, no C. En la década de los años 90 se describió la secuencia viral (2).

La infección por VHE es un problema de salud pública (3). Según la Organización Mundial de la Salud (OMS), se estiman 20 millones de casos por año de infección aguda, principalmente en Asia y África (4). La principal ruta de transmisión es la vía fecal-oral por el consumo de agua contaminada; es frecuente en zonas donde el abastecimiento de agua potable y el tratamiento de agua residual no son adecuados $(3,5)$. También puede presentarse transmisión zoonótica, siendo el cerdo el principal reservorio, por exposición ocupacional, por el consumo de carne de cerdo mal cocida y por agua contaminada con materia fecal de cerdo $(5,6)$.

En Colombia no existe un registro de la infección por el VHE, debido a que no está incluido en las guías de diagnóstico de hepatitis virales; sin embargo, existe evidencia de que el virus circula tanto en población humana como en población porcina y en fuentes de agua de abastecimiento y residuales $(3,5-8)$.

\section{GENERALIDADES Y GENOMA DEL VHE}

El VHE está clasificado en la familia Hepeviridae, género Orthohepevirus, especie Orthohepevirus A (9). Es un virus no envuelto de 27 a $34 \mathrm{~nm}$ de diámetro; aunque se ha demostrado la presencia de partículas virales con envoltura lipídica que circulan en sangre (10), lo que le permite evadir la respuesta inmune humoral $(10,11)$. Las partículas virales liberadas del hepatocito presentarían una bicapa lipídica transitoria que se pierde durante el paso por el conducto biliar debido a la presencia del ácido deoxicólico y luego en el duodeno por la presencia de proteasas; en las heces estarían presentes las partículas sin envoltura o desnudas (12).

La partícula viral desnuda tiene una alta resistencia a condiciones ambientales; una partícula viral aislada de materia fecal puede mantenerse estable a condiciones de temperatura menores de $56^{\circ} \mathrm{C}$, pero su infectividad se pierde cuando se somete a temperaturas mayores de $60^{\circ} \mathrm{C}$ (13), y a $71^{\circ} \mathrm{C}$ se logra la inactivación de partículas virales presentes en el hígado de cerdo (14). La partícula de VHE es resistente a $\mathrm{pH}$ ácido y alcalino, y a procesos de congelación y descongelación (6).

El genoma del VHE consiste en un ácido ribonucleico (ARN) lineal, de cadena sencilla y de polaridad positiva de aproximadamente 7,2 kb (6); que contiene 3 marcos de lectura abierta (open reading frame): ORF1, ORF2 y ORF3.

El ORF1 codifica una poliproteína de aproximadamente 1690 aminoácidos indispensables para la replicación del genoma viral $(6,15)$. La poliproteína se conforma de un dominio con función de metiltransferasa $(\mathrm{MeT})$, un dominio con función proteasa, un dominio con función helicasa $(\mathrm{Hel})$ y un dominio con función de polimerasa dependiente de ARN (RdRp); adicionalmente, posee un dominio $\mathrm{X}$ y otro dominio $\mathrm{Y}$ con función desconocida (6) (Figura 1). No está claro si esta poliproteína se procesa en proteínas individuales o si la actividad de los dominios se conserva en la poliproteína (16) (Tabla 1).

Tabla 1. Proteínas codificadas por el VHE y su función

\begin{tabular}{|c|c|c|}
\hline $\begin{array}{l}\text { Región del } \\
\text { genoma } \\
\text { ORF }\end{array}$ & $\begin{array}{l}\text { Dominio } \\
\text { proteico }\end{array}$ & Proceso al que influye \\
\hline ORF1 & $\begin{array}{l}\text { Metiltransferasa } \\
\text { Proteasa } \\
\text { Hel } \\
\text { RdRp } \\
X \\
\text { Y }\end{array}$ & $\begin{array}{l}\text { Replicación viral } \\
\text { Replicación viral } \\
\text { Replicación viral } \\
\text { Replicación viral } \\
\text { Función desconocida } \\
\text { Función desconocida }\end{array}$ \\
\hline ORF2 & $\begin{array}{l}S \\
M \\
P\end{array}$ & $\begin{array}{l}\text { Subunidad estructural de la cápside } \\
\text { viral }\end{array}$ \\
\hline ORF3 & - & $\begin{array}{l}\text { Interacción con el citoesqueleto } \\
\text { para la formación de la cápside, } \\
\text { ensamblaje y salida de la partícula } \\
\text { viral de la célula }\end{array}$ \\
\hline
\end{tabular}

El ORF2 codifica la subunidad estructural preORF2, que en su forma glucosilada se autoensambla para convertirse en la subunidad de la cápside viral $(6,15)$. Esta proteína

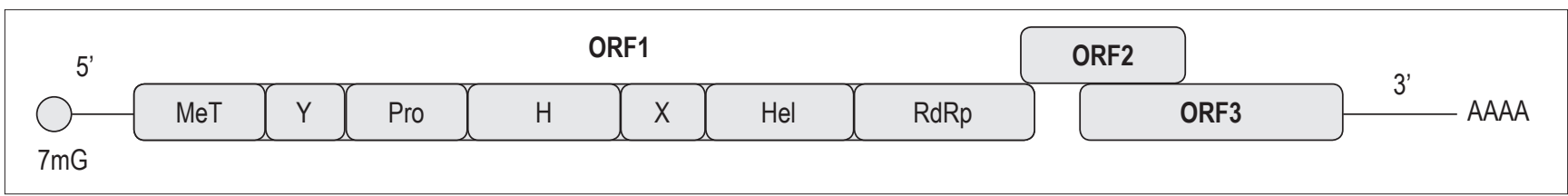

Figura 1. Organización genómica del VHE (17). H: dominio H; Pro: cisteína-papaína proteasa; X: dominio X; Y: dominio Y; $7 \mathrm{mG}$ : Cap 7-metilguanina. Modificado de: Panda SK et al. Rev Med Virol. 2007;17(3):151-80. 
presenta 3 dominios: S, My P; que están involucrados en el ensamblaje de la partícula viral y en la interacción del virus con la célula huésped $(6,16)$ (Tabla 1 ).

El ORF3 se superpone parcialmente sobre el ORF2 y codifica una pequeña proteína cuya posible función es la interacción con el citoesqueleto para los procesos de ensamblaje de la cápside y de la partícula viral $(6,18)$ (Figura 1, Tabla 1).

Existe una gran diversidad genética entre las diferentes cepas identificadas tanto en pacientes como en animales domésticos y salvajes tales como cerdos, jabalíes, venados, conejos, mangostas y camellos $(19,20)$. Se han caracterizado en pacientes 4 genotipos con una divergencia nucleotídica menor al $20 \%$ en aislados de la región del ORF2 (15) (Tabla 2).

Por una parte, los genotipos 1 y 2 se han aislado exclusivamente de muestras de origen humano obtenidas durante epidemias en Asia y África, y en México y Nigeria, respectivamente $(6,15,21)$; en Latinoamérica, se han reportado casos esporádicos de infección viral por genotipo 1 en Venezuela, Cuba y Uruguay (22-24); adicionalmente, este genotipo ha sido asociado con hepatitis fulminante, abortos y muerte en mujeres gestantes en países como India y Angola (25). Los genotipos 3 y 4 se han aislado en casos esporádicos de hepatitis en humanos, así como en animales domésticos y salvajes, lo que indica su potencial zoonótico $(15,20,21)$. Por otra parte, el genotipo 3 es el que presenta mayor distribución a nivel global en países de Asia, Europa, Oceanía y América; mientras que las únicas evidencias de infección por genotipo 4 se han documentado en Asia $(15,21)$. Recientemente, se identificó el genotipo 7 en un reporte de transmisión zoonótica por el consumo de carne y leche de camello en un paciente proveniente de Emiratos Árabes Unidos, quien había sido sometido a un trasplante de hígado (20) (Tabla 2).

El genotipo 1 se subdivide en 5 subgenotipos (designados con las letras a-e), el genotipo 2 en subgenotipos $2 a y$
$2 \mathrm{~b}$, el genotipo 3 en 10 subgenotipos (designados con las letras a-j) y el genotipo 4, en 7 subgenotipos (designados con las letras a-g) (15) (Tabla 2).

\section{REPLICACIÓN VIRAL}

La replicación del VHE comienza con la entrada de la partícula viral a la célula blanco por endocitosis mediada por un receptor (Figura 2); aunque aún no se ha identificado el receptor, se ha propuesto que los proteoglicanos heparán-sulfato (HSPG) y proteínas de choque térmico de 70 kiloDaltons (HSP70) podrían estar implicados como receptores (26).

Una vez la partícula viral se encuentra en el endosoma, debe sufrir procesos de acidificación para la degradación lipídica de la membrana por el contenido del lisosoma, específicamente por la actividad de la lipasa ácida lisosomal (LAL) (10).

Después de la entrada y la descapsidación, los 2 primeros tercios del genoma viral son traducidos para producir la pORF1 (17). Una vez sintetizado pORF1, el dominio de la RdRp sintetiza una cadena de ARN complementaria y de polaridad negativa (ARN antigenómico) que sirve como molde para la síntesis de cadenas de ARN subgenómico de 2,2 kb y cadenas de ARN genómico (17). Posteriormente, se traducen las proteínas pORF2 y pORF3 a partir del ARN subgenómico. Los dímeros de pORF2 interactúan permitiendo el autoensamblaje de la cápside; posteriormente, se realiza el empaquetamiento del genoma y la generación de nuevas partículas virales $(17,27)$ (Figura 2).

La principal célula blanco del VHE es el hepatocito; sin embargo, se ha demostrado replicación extrahepática. Estudios en animales han demostrado la presencia del genoma del VHE en órganos como el intestino delgado, colon, bazo y nódulos linfáticos en cerdos (28) y órganos como el riñón, intestino delgado, bazo y estómago en ratas (29). Adicionalmente, se ha reportado la presencia de ARN

Tabla 2. Características y distribución de los genotipos del VHE que infectan humanos

\begin{tabular}{|c|c|c|c|c|}
\hline Genotipo & Subgenotipos & Aislado & Transmisión & Patrón epidemiológico y distribución geográfica \\
\hline 1 & $a-e$ & Muestra de origen humano & Agua contaminada & $\begin{array}{l}\text { Grandes epidemias en Asia y África. Casos } \\
\text { esporádicos en América: Venezuela, Cuba y Uruguay }\end{array}$ \\
\hline 2 & $a, b$ & Muestra de origen humano & Agua contaminada & Epidemias en Nigeria y México \\
\hline 3 & $a-j$ & $\begin{array}{l}\text { Muestra de origen humano } \\
\text { y animal }\end{array}$ & $\begin{array}{l}\text { Alimentos contaminados y } \\
\text { exposición a porcinos }\end{array}$ & $\begin{array}{l}\text { Casos esporádicos en Europa y América: Estados } \\
\text { Unidos, México, Colombia, Venezuela, Brasil, Uruguay } \\
\text { Argentina, Bolivia y Perú }\end{array}$ \\
\hline 4 & $a-g$ & $\begin{array}{l}\text { Muestra de origen humano } \\
\text { y animal }\end{array}$ & $\begin{array}{l}\text { Alimentos contaminados y } \\
\text { exposición a porcinos }\end{array}$ & Casos esporádicos únicamente en Asia \\
\hline 7 & - & $\begin{array}{l}\text { Muestra de origen humano } \\
\text { y animal }\end{array}$ & $\begin{array}{l}\text { Alimentos contaminados y } \\
\text { exposición a camélidos }\end{array}$ & Casos esporádicos en África \\
\hline
\end{tabular}




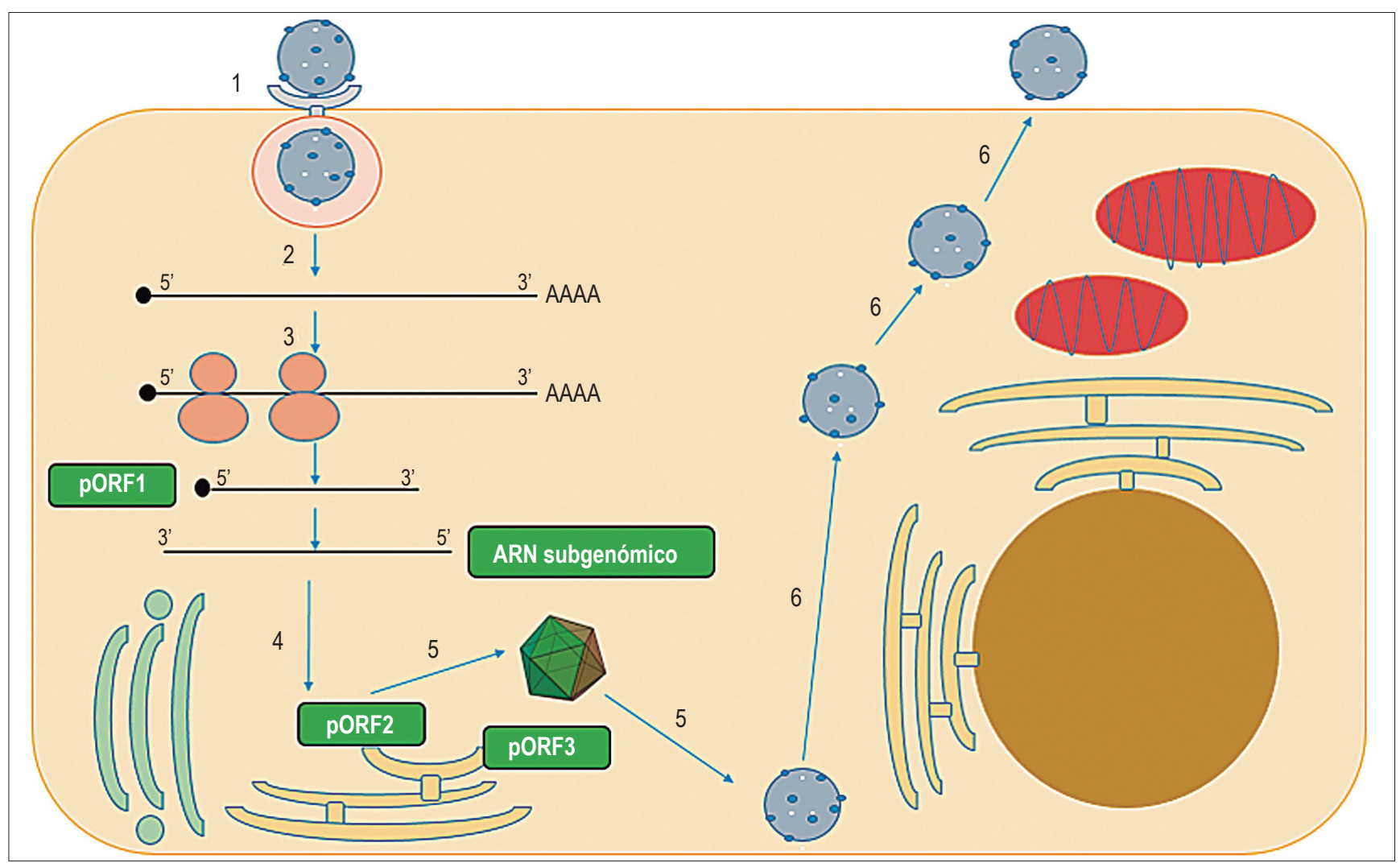

Figura 2. Esquema de la replicación del VHE. 1: entrada de la partícula viral del VHE a la célula blanco de endocitosis, mediada por un receptor; 2 : descapsidación y liberación del ARN; 3: traducción de poliproteína no estructural a partir del ORF1 (pORF1) y generación de la cadena molde de polaridad negativa y ARN subgenómico; 4: traducción de pORF2 y pORF3; 5: ensamblaje de la cápside, empaquetamiento del genoma y generación de nuevas partículas virales; 6: salida de las partículas virales de la célula. pORF1: preORF1; pORF2: preORF2; pORF3: preORF3.

genómico y antigenómico en el sistema nervioso central (SNC), lo que demuestra la replicación viral en el cerebro y la médula espinal en roedores, concomitante con necrosis de neuronas, infiltración linfocítica, invasión perineural y daños en la mielina (30).

\section{EPIDEMIOLOGÍA}

Existen 2 patrones epidemiológicos para la infección por VHE: epidémico y no epidémico (6). El patrón epidémico se ha observado principalmente en India, China, norte y occidente de África, donde la contaminación de los cuerpos de agua es la principal fuente de infección. Usualmente, la población afectada comprende adultos jóvenes entre los 15 y 30 años de edad $(6,21,31)$. En Latinoamérica, específicamente en México, solo se notificaron brotes en los años 1986 y $1987(6,21)$.

El patrón no epidémico se presenta en países industrializados, donde los casos esporádicos pueden relacionarse con el carácter zoonótico de los genotipos 3 y $4(6,21)$.

En general, en los países en desarrollo donde una parte de la población no tiene acceso al agua potable, las tasas de prevalencia son mayores que en los países desarrollados (6, $21)$. Dentro de las áreas reportadas con alta seroprevalencia en población general adulta se encuentran áreas rurales de Malasia (45\%), China (20\%-30\%), Egipto (26\%), India (20\%) y Arabia Saudita (17\%) $(6,21,32)$. En los países desarrollados se han reportado tasas de seroprevalencia inferiores en la población general adulta: en Estados Unidos 1\%-3\%, en Alemania 2,1\% $(6,21,32)$ y en España 2\%-7\% (33).

Por una parte, es importante anotar que se observan diferencias en la seroprevalencia de anticuerpos anti-VHE asociadas con riesgo ocupacional, ya que el personal veterinario y granjeros presentan una prevalencia superior a la de la población general (34-36). Un estudio en Estados Unidos demostró que el $27 \%$ de los veterinarios de 8 estados con riesgo ocupacional presentaron anticuerpos tipo inmunoglobulina G ( $\mathrm{IgG}$ ) anti-VHE comparado con los datos de seroprevalencia anti-VHE en donantes de sangre en este mismo país (37); adicionalmente, en Moldavia se describe una prevalencia del $51 \%$ para anticuerpos tipo IgG antiVHE en trabajadores de granjas porcícolas comparado con $25 \%$ de seroprevalencia en el grupo control, sin exposición ocupacional a porcinos (36). En Colombia se ha demos- 
trado que la prevalencia de anticuerpos tipo IgG anti-VHE para trabajadores de granjas porcícolas varía entre un $11,25 \%$ y $15,7 \%(35,38)$; por el contrario, se ha reportado una prevalencia de $2,5 \%$ para anticuerpos tipo inmunoglobulina M (IgM) anti-VHE en esta misma población (38). Por otra parte, existe evidencia serológica de la infección por este virus en población conviviente con trabajadores de granjas porcícolas en un porcentaje de 5,9 para anticuerpos tipo IgG anti-VHE (38) (Tabla 3).

Estudios realizados en el país han reportado una seroprevalencia en población porcina de $100 \%$ para anticuerpos tipo IgG y de 57\% para anticuerpos tipo IgM anti-VHE.

Tabla 3. Estudios de infección por VHE realizados en Colombia

\begin{tabular}{|c|c|c|c|c|}
\hline Población de estudio/muestras & $\begin{array}{c}\text { Genotipol } \\
\text { subgenotipo }\end{array}$ & Evidencia serológica & Detección de ARN viral por RT-PCR & Referencia \\
\hline $\begin{array}{l}\text { Pacientes con diagnóstico clínico de } \\
\text { hepatitis viral atendidos en } 5 \text { centros } \\
\text { de salud/hospital de Medellín. } \\
\text { Estudio prospectivo }\end{array}$ & 3 & - & $\begin{array}{l}22,5 \% \text { ( } 9 / 40 \text { muestras de materia fecal) } \\
\text { RT-PCR ORF1 y ORF2/3 }\end{array}$ & $(39)$ \\
\hline $\begin{array}{l}\text { Pacientes con diagnóstico clínico } \\
\text { de hepatitis viral proveniente de } 16 \\
\text { departamentos de Colombia. Estudio } \\
\text { retrospectivo }\end{array}$ & - & $\begin{array}{l}1,74 \% \text { lgM anti-VHE (6/344 muestras) } \\
7,5 \% \text { lgG anti-VHE (26/344 muestras) }\end{array}$ & - & $(40)$ \\
\hline $\begin{array}{l}\text { Trabajadores de fincas porcícolas en } \\
\text { el Valle de Aburrá }\end{array}$ & - & $11,25 \%$ lgG anti-VHE & - & $(35)$ \\
\hline $\begin{array}{l}\text { Población porcina de plantas de } \\
\text { beneficio en Antioquia }\end{array}$ & - & $\begin{array}{l}100 \% \lg G \text { anti-VHE } \\
57 \% \lg M \text { anti-VHE }\end{array}$ & $\begin{array}{l}26 \% \text { ( } 41 / 152 \text { muestras de materia } \\
\text { fecal) } \\
\text { RT-PCR ORF1 }\end{array}$ & $(5)$ \\
\hline \multirow[t]{3}{*}{$\begin{array}{l}\text { Población con o sin riesgo } \\
\text { ocupacional (granjas porcícolas) }\end{array}$} & - & $\begin{array}{l}\text { Riesgo ocupacional: } \\
15,7 \% \lg \mathrm{G} \text { anti-VHE } \\
2,5 \% \text { IgM anti-VHE }\end{array}$ & - & $(38)$ \\
\hline & & $\begin{array}{l}\text { Convivientes de expuestos a porcinos } \\
\text { por riesgo ocupacional: } \\
5,9 \% \lg \text { anti-VHE }\end{array}$ & & \\
\hline & & $\begin{array}{l}\text { Población general: } \\
7,2 \% \lg G \text { anti-VHE } \\
0,81 \% \text { lgM anti-VHE }\end{array}$ & & \\
\hline $\begin{array}{l}\text { Población porcina de granjas en el } \\
\text { departamento de Antioquia }\end{array}$ & $3 a$ & - & $\begin{array}{l}41,2 \% \text { ( } 124 / 300 \text { muestras de heces) y } \\
59,9 \% \text { ( } 180 / 300 \text { muestras de hígado) } \\
\text { RT-PCR ORF1 y ORF2 }\end{array}$ & $(41)$ \\
\hline \multirow{2}{*}{$\begin{array}{l}\text { Pacientes con infección por VHA, } \\
\text { VHB o VHC }\end{array}$} & \multirow[t]{2}{*}{$3 a$} & $\begin{array}{l}31,2 \% \lg \mathrm{G} \text { anti-VHE } \\
11,5 \% \lg \mathrm{M} \text { anti-VHE }\end{array}$ & $37 \%$ (94/255 muestras de suero) & $(42)$ \\
\hline & & $\begin{array}{l}11,5 \% \text { IgIV antl-VHE } \\
\text { Marcadores de coinfección: } \\
49 \% \text { anti-VHE-IgM anti-VHA } \\
31 \% \text { anti-VHE-HBsAg anti-VHB } \\
41 \% \text { anti-VHE-RIBA anti-VHC }\end{array}$ & RT-PCR ORF1 (MeT y RdRp) ORF2 & \\
\hline $\begin{array}{l}\text { Agua de abastecimiento y agua } \\
\text { residual de } 9 \text { municipios de } \\
\text { Antioquia. Un municipio de cada } \\
\text { subregión de Antioquia }\end{array}$ & 3 & - & $\begin{array}{l}16,6 \% \text { ( } 5 / 30 \text { muestras de agua } \\
\text { residual) y } 23,3 \% \text { ( } 7 / 30 \text { muestras de } \\
\text { agua de abastecimiento) RT-PCR } \\
\text { ORF2/3 }\end{array}$ & (8) \\
\hline $\begin{array}{l}\text { Donantes de sangre del municipio } \\
\text { de Yarumal, Antioquia }\end{array}$ & - & $\begin{array}{l}45,2 \% \lg G \text { anti-VHE } \\
0 \% \lg M \text { anti-VHE }\end{array}$ & - & $(43)$ \\
\hline
\end{tabular}

HBsAg: antígeno de superficie de la hepatitis B; RIBA: Recombinant Immuno Assay; RT-PCR: reacción en cadena de la polimerasa con transcriptasa inversa; VHA: virus de la hepatitis A; VHB: virus de la hepatitis B; VHC: virus de la hepatitis C. 
Adicionalmente, hay evidencia molecular que demuestra la presencia del genoma del virus en muestras de heces de población porcina en un rango entre el $26 \%$ y el $41 \%$, y en muestras de hígado de la misma población en un $60 \%(15,44)$. Las secuencias amplificadas y aisladas de población porcina se agrupan en el genotipo 3 subgenotipo 3a (15) (Tabla 3).

En pacientes existe evidencia serológica y molecular de infección por VHE; se ha reportado la amplificación del genoma viral de $22,5 \%$ de las muestras de materia fecal analizadas que permite establecer la circulación de genotipo 3 (39). En cuanto a la evidencia serológica, se ha reportado un rango entre 7,5\% y $31,2 \%$ para anticuerpos tipo IgG anti-VHE y $1,74 \%$ y $11,5 \%$ para anticuerpos tipo IgM antiVHE $(40,42)$ (Tabla 3).

Además, en donantes de sangre de zona rural en Antioquia (Yarumal), 45,2\% de las muestras analizadas fueron positivas para la presencia de anticuerpos anti-VHE tipo IgG (43) (Tabla 3).

El VHE también ha sido detectado en fuentes de agua de abastecimiento y en agua residual en el departamento de Antioquia. De 60 muestras analizadas, el 20\% (12/60) fue positiva para la detección del genoma de VHE por RT-PCR. Se caracterizó el genotipo 3 en las muestras provenientes de los municipios de San Pedro de los Milagros, Venecia y Cisneros (8) (Tabla 3).

\section{PERFIL CLÍNICO}

En la mayoría de los pacientes, el VHE causa una infección autolimitada y generalmente asintomática $(6,31)$. El período de incubación es de 15 a 60 días, con una media de 40 días, en el que se desarrollan los signos y síntomas como fiebre, náuseas, dolor abdominal, vómito, malestar $\mathrm{y}$, en algunos casos, hepatomegalia $(6,31,45)$.

El 75\% de los pacientes con una infección aguda presentan ictericia entre la segunda y la cuarta semana después de la infección $(6,31)$ (Tabla 4). El VHE puede detectarse en heces antes del inicio de los síntomas y hasta por 5 semanas después, mientras que el ARN viral en suero es detectable hasta 3 semanas después del inicio de los síntomas (46, 47). Los anticuerpos tipo IgM anti-VHE pueden detectarse durante la fase aguda de la enfermedad, específicamente a partir del cuarto día después del inicio de la ictericia y hasta 5 meses después de la infección (48). Los anticuerpos tipo IgG anti-VHE pueden aparecer simultáneamente a la respuesta de anticuerpos tipo IgM, que aumenta a lo largo de la fase aguda y permanece años después de la infección; sin embargo, se desconoce la duración exacta de los anticuerpos tipo IgG (48). La aparición de anticuerpos anti-VHE en suero coincide con el período en el que se elevan las transaminasas en suero (46) (Figura 3).

Tabla 4. Infección aguda y crónica por VHE

\begin{tabular}{|c|c|c|c|c|}
\hline & $\begin{array}{l}\text { Genotipo } \\
\text { causante }\end{array}$ & Características de los pacientes & Características de la infección & Manifestaciones extrahepáticas \\
\hline $\begin{array}{l}\text { Infección } \\
\text { aguda }\end{array}$ & $1,2,3,4$ & $\begin{array}{l}\text { Pacientes entre } 15 \text { y } 30 \text { años } \\
\text { presentan una infección causada por } \\
\text { genotipos } 1 \text { y } 2 \text {. Pacientes mayores a } \\
30 \text { años generalmente presentan una } \\
\text { infección causada por genotipos } 3 \text { y } 4\end{array}$ & $\begin{array}{l}\text { Síntomas como fiebre, náuseas, } \\
\text { dolor abdominal, vómito e ictericia } \\
\text { lgM anti-VHE entre la segunda y la } \\
\text { cuarta semana postinfección }\end{array}$ & $\begin{array}{l}\text { Desórdenes neurológicos: } \\
\text { Síndrome de Guillain-Barré } \\
\text { Parálisis de Bell } \\
\text { Amiotrofia neurálgica } \\
\text { Mielitis transversa aguda } \\
\text { Encefalitis } \\
\text { Desórdenes hematológicos: } \\
\text { Trombocitopenia } \\
\text { Anemia aplásica } \\
\text { Pancreatitis } \\
\text { Lesiones renales: } \\
\text { Glomerulonefritis }\end{array}$ \\
\hline $\begin{array}{l}\text { Infección } \\
\text { crónica }\end{array}$ & 3 & $\begin{array}{l}\text { Pacientes con déficit en el sistema } \\
\text { inmune por: } \\
\text { Terapia de inmunosupresión por } \\
\text { trasplante } \\
\text { Infección por VIH } \\
\text { Quimioterapia } \\
\text { Leucemia }\end{array}$ & $\begin{array}{l}\text { Fatiga como síntoma principal y } \\
\text { aumento de las enzimas hepáticas. } \\
\text { La infección puede progresar a } \\
\text { cirrosis } \\
\text { Alta concentración de anticuerpos } \\
\operatorname{lgG} \text { anti-VHE }\end{array}$ & $\begin{array}{l}\text { Desórdenes neurológicos: } \\
\text { Síndrome de Guillain-Barré } \\
\text { Parálisis de Bell } \\
\text { Amiotrofia neurálgica } \\
\text { Mielitis transversa aguda } \\
\text { Encefalitis } \\
\text { Lesiones renales: } \\
\text { Glomerulonefritis }\end{array}$ \\
\hline
\end{tabular}

VIH: virus de la inmunodeficiencia humana. 


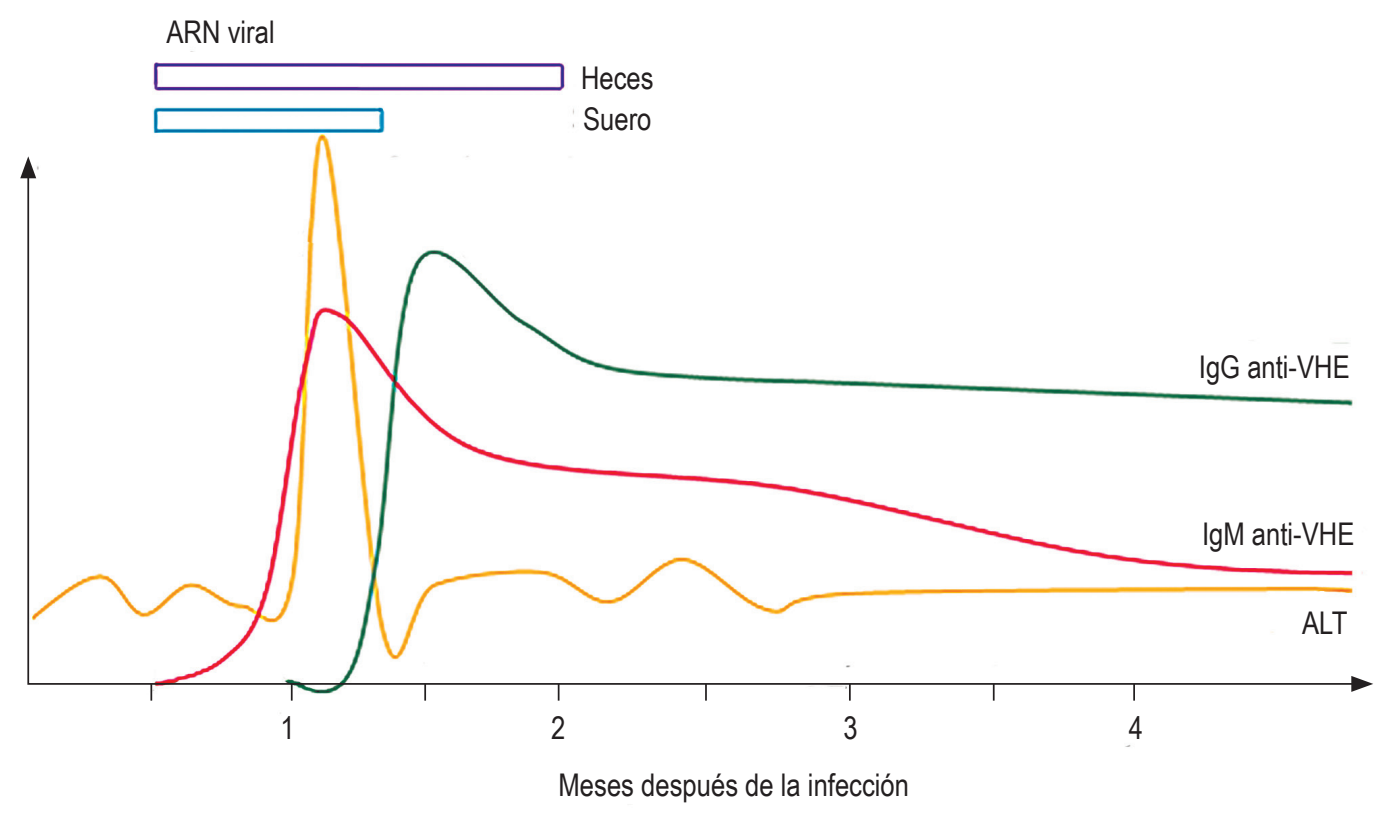

Figura 3. Marcadores serológicos y moleculares en el transcurso de la infección por VHE (49). ALT: alanina aminotransferasa. Modificado de: Aggarwal R. Semin Liver Dis. 2013;33(1):30-40.

La infección crónica se ha asociado con el genotipo 3 en pacientes que reciben terapia de inmunosupresión por trasplante de órganos, pacientes infectados con el VIH y pacientes que están recibiendo quimioterapia (50-52) (Tabla 4). Se debe tener en cuenta que el peso epidemiológico aún es desconocido, pero se sugiere que los pacientes con terapia de inmunosupresión por trasplante de órganos e infección por VHE pueden presentar una rápida progresión de la fibrosis hepática y evolución a cirrosis $(52,53)$.

Debido a esto, se propone una primera línea de tratamiento que consiste en una reducción de la terapia inmunosupresora, teniendo en cuenta que los medicamentos inmunosupresores como la ciclosporina $\mathrm{A}$, tacrolimus y everolimus favorecen la replicación del VHE; y, por el contrario, el ácido micofenólico bloquea la actividad antiviral $(53,54)$. Si el paciente no logra resolver la infección con esta estrategia, se procede al tratamiento antiviral con ribavirina por 3 meses, que ha demostrado buenos resultados; no obstante, puede presentarse resistencia antiviral asociada con mutaciones como $\mathrm{G} 1634 \mathrm{R}(53,55)$. Se ha propuesto la terapia con interferón tipo I pegilado, que ha demostrado in vitro una actividad antiviral moderada contra el VHE (53). Por último, el medicamento sofosbuvir ha demostrado capacidad para inhibir la replicación del virus y la actividad antiviral aumenta cuando se combina con ribavirina (56).

La hepatitis E es clínicamente indistinguible de los otros tipos de hepatitis virales, por lo que el diagnóstico requiere de pruebas serológicas y moleculares (6). Las pruebas sero- lógicas se basan en la detección por inmunoensayo de anticuerpos anti-VHE tipo IgG e IgM, que usan como blanco proteínas recombinantes o péptidos del VHE correspondientes a epítopos de pORF2 $(6,47,48)$. Es de resaltar que algunos estudios han demostrado resultados discordantes en la sensibilidad, incluso algunos no detectan anticuerpos tipo IgM en pacientes infectados con VHE, por lo que se genera un resultado de falso negativo. Estas diferencias entre pruebas serológicas disponibles se podrían explicar por la diversidad genotípica; por diferencias en los antígenos utilizados, puesto que los antígenos utilizados en los estuches comerciales solo provienen de genotipo 1 o 3 ; y por la metodología empleada $(47,49)$; lo que demuestra que las pruebas serológicas disponibles varían en sensibilidad y especificidad, complicando la interpretación de los resultados $(47,49)$. Por tal motivo se recomienda que, siempre que se vaya a hacer un diagnóstico para VHE, se deben emplear tanto las técnicas serológicas como moleculares para garantizar que no existan resultados con falsos negativos (47).

\section{MANIFESTACIONES EXTRAHEPÁTICAS}

Recientemente, se ha asociado el VHE con manifestaciones extrahepáticas tales como desórdenes neurológicos y hematológicos, lesiones renales y pancreatitis (Tabla 4).

Algunas de las manifestaciones neurológicas observadas en pacientes con infección aguda y crónica causada por VHE son el síndrome de Guillain-Barré, un trastorno 
autoinmune que afecta principalmente la mielina $(57,58)$; parálisis de Bell, debido al daño o trauma de los nervios faciales que ocasiona parálisis facial (59); amiotrofia neurálgica y neuritis braquial bilateral que afecta principalmente los hombros $(57,60)$; y mielitis transversa aguda causada por un proceso inflamatorio en la médula (61).

En un estudio retrospectivo que incluyó 126 pacientes con infección aguda y crónica por VHE, se reportaron diferentes manifestaciones neurológicas en un 5,5\% (7/126) de los pacientes, como el síndrome de Guillain-Barré, neuritis braquial bilateral y encefalitis (62); 3 de los casos correspondían a pacientes con infección aguda por VHE sin ningún tipo de inmunosupresión, mientras que los 4 casos restantes eran pacientes inmunocomprometidos con infección crónica por VHE (62). En este mismo estudio se reportó la presencia de ARN viral en fluido cerebroespinal en 4 pacientes con infección crónica por VHE, lo que sugirió replicación y el posible paso de la barrera hematoencefálica (62).

Con respecto a los desórdenes hematológicos, se han documentado casos de infección aguda por VHE en los que se evidencia trombocitopenia (63), además de anemia aplásica (64).

Se han descrito daños en la función renal en pacientes con infección aguda o crónica por VHE, principalmente en pacientes con trasplante de hígado o pacientes con ingesta de medicamentos que comprometen la función renal (65), causando enfermedades como glomerulonefritis (65).

Por último, se han reportado casos de pancreatitis en pacientes que presentan una infección aguda por genotipo 1 del VHE (66).

\section{CONCLUSIÓN}

Es necesario alertar al personal médico sobre la importancia de incluir el VHE en el diagnóstico de hepatitis virales en Colombia; dado que existe evidencia de la circulación del virus en pacientes, donantes de sangre, trabajadores de granjas porcícolas, población conviviente con trabajadores de granjas porcícolas, población porcina y fuentes de agua de abastecimiento y residual. Aunque esta infección es autolimitada en la mayoría de los casos, también puede progresar a infección crónica o cirrosis. Además, es importante describir la epidemiología de una infección emergente en la población para el control de este virus.

\section{Agradecimientos}

Al doctor Rafael Claudino Botero por la revisión del manuscrito.

\section{Financiación}

Este artículo hace parte del proyecto de investigación financiado por Colciencias (Cod.111554531673) y la Universidad de Antioquia.

\section{Conflicto de intereses}

Los autores declaran no tener conflictos de intereses.

\section{REFERENCIAS}

1. Balayan MS, Andjaparidze AG, Savinskaya SS, et al. Evidence for a virus in non-A, non-B hepatitis transmitted via the fecal-oral route. Intervirology. 1983;20(1):23-31. https://doi.org/10.1159/000149370.

2. Reyes GR, Purdy MA, Kim JP, et al. Isolation of a cDNA from the virus responsible for enterically transmitted non-A, non-B hepatitis. Science. 1990;247(4948):1335-9. https:// doi.org/10.1126/science.2107574.

3. Echevarría JM, González JE, Lewis-Ximenez LL, et al. Hepatitis E virus infection in Latin America: a review. J Med Virol. 2013;85(6):1037-45. https://doi.org/10.1002/ jmv.23526.

4. Organización Mundial de la Salud. Hepatitis E. OMS [Internet] 2016 [acceso el 4 de febrero de 2016]. Disponible en: http://www.who.int/mediacentre/factsheets/fs280/es/.

5. Gutiérrez CC, Ospina DA, Forero JE, et al. Detección serológica y molecular del virus de la Hepatitis $\mathrm{E}$ en cerdos de granjas antioqueñas. CES Med Vet Zootec. 2014;9(2):158-68.

6. Rodríguez F, Jardi R, Buti M. Hepatitis E: virología molecular, epidemiología y patogénesis. Enferm Infecc Microbiol Clin. 2012;30(10):624-34. https://doi.org/10.1016/j. eimc.2012.01.014.

7. Forero J, Gutiérrez C, Parra J, et al. Evidencia serológica de infección por el virus de hepatitis $\mathrm{E}$ en cerdos faenados en Antioquia, Colombia. Rev MVZ Córdoba. 2015;20(2):4602-13. https://doi.org/10.21897/rmvz.63.

8. Báez P, Jaramillo CM, Arismendi L, et al. Evidencia molecular de virus de la hepatitis $\mathrm{E}$ en fuentes de agua en Antioquia. Biomédica. 2015;35(Supl 1):40-1.

9. International Committee on Taxonomy of Viruses. ICTV taxonomy history: Orthohepevirus A.ICTV [Internet] 2016 [acceso el 10 de febrero de 2016]. Disponible en: http:// www.ictvonline.org/taxonomyHistory.asp?taxnode $\mathrm{id}=20142432 \&$ taxa name $=$ Orthohepevirus\%20A.

10. Yin X, Ambardekar $\bar{C}, \mathrm{Lu} Y$, et al. Distinct entry mechanisms for nonenveloped and quasi-enveloped hepatitis $\mathrm{E}$ viruses. J Virol. 2016;90(8):4232-42. https://doi.org/10.1128/ JVI.02804-15.

11. Takahashi M, Tanaka T, Takahashi H, et al. Hepatitis E Virus (HEV) strains in serum samples can replicate efficiently in cultured cells despite the coexistence of HEV antibodies: 
characterization of HEV virions in blood circulation. J Clin Microbiol. 2010;48(4):1112-25. https://doi.org/10.1128/ JCM.02002-09.

12. Okamoto H. Culture systems for hepatitis $\mathrm{E}$ virus. J Gastroenterol. 2013;48(2):147-58. https://doi.org/10.1007/ s00535-012-0682-0.

13. Emerson SU, Arankalle VA, Purcell RH. Thermal stability of hepatitis E virus. J Infect Dis. 2005;192(5):930-3. https:// doi.org/10.1086/432488.

14. Barnaud E, Rogée S, Garry P, et al. Thermal inactivation of infectious hepatitis $\mathrm{E}$ virus in experimentally contaminated food. Appl Environ Microbiol. 2012;78(15):5153-9. https://doi.org/10.1128/AEM.00436-12.

15. Lu L, Li C, Hagedorn CH. Phylogenetic analysis of global hepatitis E virus sequences: genetic diversity, subtypes and zoonosis. Rev Med Virol. 2006;16(1):5-36. https://doi. org/10.1002/rmv.482.

16. Holla RP, Ahmad I, Ahmad Z, et al. Molecular virology of hepatitis E virus. Semin Liver Dis. 2013;33(1):3-14. https://doi.org/10.1055/s-0033-1338110.

17. Panda SK, Thakral D, Rehman S. Hepatitis E virus. Rev Med Virol. 2007;17(3):151-80. https://doi.org/10.1002/ rmv.522.

18. Zafrullah M, Ozdener MH, Panda SK, et al. The ORF3 protein of hepatitis $\mathrm{E}$ virus is a phosphoprotein that associates with the cytoskeleton. J Virol. 1997;71(12):9045-53.

19. Schlauder GG, Mushahwar IK. Genetic heterogeneity of hepatitis E virus. J Med Virol. 2001;65(2):282-92. https:// doi.org/10.1002/jmv.2031.

20. Lee GH, Tan BH, Teo EC, et al. chronic infection with camelid hepatitis $\mathrm{E}$ virus in a liver transplant recipient who regularly consumes camel meat and milk. Gastroenterology. 2016;150(2):355-7.e3. https://doi.org/10.1016/S0016-5085(16)31244-6 https://doi.org/10.1053/j.gastro.2015.10.048.

21. Aggarwal R, Naik S. Epidemiology of hepatitis E: current status. J Gastroenterol Hepatol. 2009;24(9):1484-93. https://doi.org/10.1111/j.1440-1746.2009.05933.x.

22. García CG, Sánchez D, Villalba MC, et al. Molecular characterization of hepatitis $\mathrm{E}$ virus in patients with acute hepatitis in Venezuela. J Med Virol. 2012;84(7):1025-9. https://doi. org/10.1002/jmv.23277.

23. Mirazo S, Mainardi V, Ramos N, et al. Indigenous hepatitis $\mathrm{E}$ virus genotype 1 infection, Uruguay. Emerg Infect Dis. 2014;20(1):171-3.https://doi.org/10.3201/eid2001.131471.

24. Villalba Mde L, Lay Lde L, Chandra V, et al. Hepatitis E virus genotype 1, Cuba. Emerg Infect Dis. 2008;14(8):1320-2. https://doi.org/10.3201/eid1408.080049.

25. Navaneethan U, Al Mohajer M, Shata MT. Hepatitis E and pregnancy: understanding the pathogenesis. Liver Int. 2008;28(9):1190-9. https://doi.org/10.1111/j.14783231.2008.01840.x.

26. Kalia M, Chandra V, Rahman SA, et al. Heparan sulfate proteoglycans are required for cellular binding of the hepatitis E virus ORF2 capsid protein and for viral infection. J
Virol. 2009;83(24):12714-24. https://doi.org/10.1128/ JVI.00717-09.

27. Li TC, Takeda N, Miyamura T, et al. Essential elements of the capsid protein for self-assembly into empty virus-like particles of hepatitis E virus. J Virol. 2005;79(20):12999-3006. https://doi.org/10.1128/JVI.79.20.12999-13006.2005.

28. Williams TP, Kasorndorkbua C, Halbur PG, et al. Evidence of extrahepatic sites of replication of the hepatitis $\mathrm{E}$ virus in a swine model. J Clin Microbiol. 2001;39(9):3040-6. https://doi.org/10.1128/JCM.39.9.3040-3046.2001.

29. Liu $\mathrm{P}, \mathrm{Bu} \mathrm{QN}$, Wang L, et al. Transmission of hepatitis $\mathrm{E}$ virus from rabbits to cynomolgus macaques. Emerg Infect Dis. 2013;19(4):559-65. https://doi.org/10.3201/ eid1904.120827.

30. Shi R, Soomro MH, She R, et al. Evidence of hepatitis E virus breaking through the blood-brain barrier and replicating in the central nervous system. J Viral Hepat. 2016;23(11):930-9. https://doi.org/10.1111/jvh.12557.

31. Purcell RH, Emerson SU. Hepatitis E: an emerging awareness of an old disease. J Hepatol. 2008;48(3):494-503. https://doi.org/10.1016/j.jhep.2007.12.008.

32. Bihl F, Negro F. Hepatitis E virus: a zoonosis adapting to humans. J Antimicrob Chemother. 2010;65(5):817-21. https://doi.org/10.1093/jac/dkq085.

33. Fogeda M, Avellón A, Echevarría JM. Prevalence of specific antibody to hepatitis E virus in the general population of the community of Madrid, Spain. J Med Virol. 2012;84(1):71-4. https://doi.org/10.1002/jmv.22270.

34. Meng XJ. Hepatitis E virus: animal reservoirs and zoonotic risk. Vet Microbiol. 2010;140(3-4):256-65. https://doi. org/10.1016/j.vetmic.2009.03.017.

35. Betancur CA, Mejía MV, Portillo S. Seroprevalencia de hepatitis E en trabajadores de fincas porcícolas del Valle de Aburrá 2011-2012. Acta Médica Colomb. 2013;38(2):68-70.

36. Drobeniuc J, Favorov MO, Shapiro CN, et al. Hepatitis E virus antibody prevalence among persons who work with swine. J Infect Dis. 2001;184(12):1594-7. https://doi. org/10.1086/324566.

37. Meng XJ, Wiseman B, Elvinger F, et al. Prevalence of antibodies to hepatitis $\mathrm{E}$ virus in veterinarians working with swine and in normal blood donors in the United States and other countries. J Clin Microbiol. 2002;40(1):117-22. https://doi.org/10.1128/JCM.40.1.117-122.2002.

38. Gutiérrez CC, Rodríguez B, Parra J, et al. Determinación de anticuerpos totales (IgG/IgM) y específicos (IgM) para el virus de la hepatitis $\mathrm{E}$ y detección molecular del virus en heces de humanos con o sin exposición ocupacional a porcinos en 10 municipios de Antioquia. Iatreia. 2015;28(3):248-58.

39. Rendon J, Hoyos MC, di Filippo D, et al. Hepatitis E Virus Genotype 3 in Colombia: Survey in Patients with Clinical Diagnosis of Viral Hepatitis. PLoS One. 2016;11(2):e0148417. https://doi.org/10.1371/journal. pone.0148417.

40. Peláez D, Martínez D, Escalante $M$, et al. Coinfección del virus de la hepatitis $\mathrm{E}$ con otras hepatitis virales en 
Colombia y su caracterización genotípica. Biomédica. 2016;36(Supl):2-30.

41. Forero JE, Gutiérrez-Vergara C, Parra Suescún J, et al. Phylogenetic analysis of Hepatitis $\mathrm{E}$ virus strains isolated from slaughter-age pigs in Colombia. Infect Genet Evol. 2017;49:138-45. https://doi.org/10.1016/j.meegid.2017.01.005.

42. Peláez D, Hoyos MC, Rendón JC, et al. Infección por el virus de la hepatitis $\mathrm{E}$ en pacientes con diagnóstico clínico de hepatitis viral en Colombia. Biomédica. 2014;34(3):354-65. https://doi.org/10.7705/biomedica.v34i3.2236.

43. Duque A, Restrepo LF, Mantilla C, et al. Frecuencia de anticuerpos contra el virus de la hepatitis $\mathrm{E}$ en donantes de sangre del municipio de Yarumal, Antioquia. Rev Colomb Gastroenterol. 2016;31(3):229-34.

44. Forero JE, Parra JE, López A. Detección del genoma del virus de la hepatitis e (VHE) en muestras de heces de cerdos en plantas de beneficio de Antioquia, Colombia. Rev Med Vet Zoot. 2014;61(3):221-7. https://doi.org/10.15446/ rfmvz.v61n3.46868.

45. Teshale EH, Hu DJ, Holmberg SD. The two faces of hepatitis E virus. Clin Infect Dis. 2010;51(3):328-34. https://doi. org/10.1086/653943.

46. Krawczynski K, Meng XJ, Rybczynska J. Pathogenetic elements of hepatitis $\mathrm{E}$ and animal models of HEV infection. Virus Res. 2011;161(1):78-83. https://doi.org/10.1016/j. virusres.2011.03.007.

47. Cattoir L, Van Hoecke F, Van Maerken T, et al. Hepatitis E virus serology and PCR: does the methodology matter? Arch Virol. 2017;162(9):2625-32. https://doi.org/10.1007/ s00705-017-3395-0.

48. Khudyakov Y, Kamili S. Serological diagnostics of hepatitis E virus infection. Virus Res. 2011;161(1):84-92. https:// doi.org/10.1016/j.virusres.2011.06.006.

49. Aggarwal R. Hepatitis E: clinical presentation in diseaseendemicareasanddiagnosis.SeminLiverDis.2013;33(1):3040. https://doi.org/10.1055/s-0033-1338112.

50. Kamar N, Mansuy JM, Cointault O, et al. Hepatitis E virusrelated cirrhosis in kidney- and kidney-pancreas-transplant recipients. Am J Transplant. 2008;8(8):1744-8. https://doi. org/10.1111/j.1600-6143.2008.02286.x.

51. Gérolami R, Moal V, Picard C, et al. Hepatitis E virus as an emerging cause of chronic liver disease in organ transplant recipients. J Hepatol. 2009;50(3):622-4. https://doi. org/10.1016/j.jhep.2008.12.008.

52. Kamar N, Garrouste C, Haagsma EB, et al. Factors associated with chronic hepatitis in patients with hepatitis $\mathrm{E}$ virus infection who have received solid organ transplants. Gastroenterology. 2011;140(5):1481-9. https://doi. org/10.1053/j.gastro.2011.02.050.
53. Kamar N, Lhomme S, Abravanel F, et al. Treatment of $\mathrm{HEV}$ infection in patients with a solid-organ transplant and chronic hepatitis. Viruses. 2016;8(8). https://doi. org/10.3390/v8080222.

54. Wang Y, Zhou X, Debing Y, et al. Calcineurin inhibitors stimulate and mycophenolic acid inhibits replication of hepatitis E virus. Gastroenterology. 2014;146(7):1775-83. https://doi.org/10.1053/j.gastro.2014.02.036.

55. Debing Y, Ramière C, Dallmeier $\mathrm{K}$, et al. Hepatitis E virus mutations associated with ribavirin treatment failure result in altered viral fitness and ribavirin sensitivity. J Hepatol. 2016;65(3):499-508. https://doi.org/10.1016/j. jhep.2016.05.002.

56. Dao Thi VL, Debing Y, Wu X, et al. Sofosbuvir inhibits hepatitis $\mathrm{E}$ virus replication in vitro and results in an additive effect when combined with ribavirin. Gastroenterology. 2016;150(1):82-85.e4. https://doi.org/10.1053/j.gastro.2015.09.011.

57. Cheung MC, Maguire J, Carey I, et al. Review of the neurological manifestations of hepatitis E infection. Ann Hepatol. 2012;11(5):618-22.

58. Chalupa P, Holub M.Jaundice complicated by an atypical form of Guillain-Barré syndrome. J Clin Virol. 2010;49(4):229-30. https://doi.org/10.1016/j.jcv.2010.07.017.

59. Jha AK, Nijhawan S, Nepalia S, et al. Association of Bell's palsy with hepatitis $\mathrm{E}$ virus infection: a rare entity. J Clin Exp Hepatol. 2012;2(1):88-90. https://doi.org/10.1016/ S0973-6883(12)60082-6.

60. Fong F, Illahi M. Neuralgic amyotrophy associated with hepatitis E virus. Clin Neurol Neurosurg. 2009;111(2):193-5. https://doi.org/10.1016/j.clineuro.2008.09.005.

61. Mandal K, Chopra N. Acute transverse myelitis following hepatitis E virus infection. Indian Pediatr. 2006;43(4):365-6.

62. Kamar N, Bendall RP, Peron JM, et al. Hepatitis E virus and neurologic disorders. Emerg Infect Dis. 2011;17(2):173-9. https://doi.org/10.3201/eid1702.100856.

63. Colson P, Payraudeau E, Leonnet C, et al. Severe thrombocytopenia associated with acute hepatitis $\mathrm{E}$ virus infection. J Clin Microbiol. 2008;46(7):2450-2. https://doi. org/10.1128/JCM.02295-07.

64. Shah SA, Lal A, Idrees $M$, et al. Hepatitis E virus-associated aplastic anaemia: the first case of its kind. J Clin Virol. 2012;54(1):96-7. https://doi.org/10.1016/j.jcv.2012.02.002.

65. Kamar N, Weclawiak H, Guilbeau-Frugier C, et al. Hepatitis $\mathrm{E}$ virus and the kidney in solid-organ transplant patients. Transplantation. 2012;93(6):617-23. https://doi. org/10.1097/TP.0b013e318245f14c.

66. Deniel C, Coton T, Brardjanian S, et al. Acute pancreatitis: a rare complication of acute hepatitis E. J Clin Virol. 2011;51(3):2024. https://doi.org/10.1016/j.jcv.2011.04.009. 